With a multipurpose atrium linking it to Old Chancellor Day Hall on Peel Street, the Nahum Gelber Law Library is described in a commemorative brochure as a "suitable consort [for surrounding mansions], with its dark seriousness, dignity and occasional touches of whimsy." Hanganu himself has said it is "a box - a simple box" conceived to reveal inward beality and gravity of purpose "for people who come to read and learn - and grow."

According to Toope, the Library is, however, much more than a box - it is a catalyst for the Faculty which, poised to mark its $150^{\text {th }}$ anniversary throughout the 1998-99 academic year, is plunging into cyberspace with remarkable enthusiasm. Every one of its 350 work stations, for example, is wired for laptops and connected to the Internet, with user-friendiy technology support "instantly visible as you walk in," he notes. Toope and Law Librarian Robert Clarke point out that students have been deeply involved in the project, influencing the Library's design to an exceptional degree and helping to ensure that it is the first completely barrier-free library in the entire University.

Implementing the Gaculty's new curriculum will continue the momentum forward during 1998-99 and beyond. "Our recent revisions are dramatic, but they're based or wide consultation and, in my view, show tremendous courage and creativity. Students will have more choice, and the two great legal systems of the Western world, common law and civil law, will truly illuminate one another, almost in a dialogue, right from the first year of study," says the Dean.

\title{
Walter Hitschfeld Geographic Information Centre
}

\author{
By Carol Marley \\ Information Services Librarian
}

November 14, 1997 saw the official opening of the new Walter Hitschfeld Geographic Information Centre (GIC). Occupying the entire fifth floor of Burnside Hall, the GIC combines the former Walter Hitschfeld Environmental Earth Sciences Library with the new GIC Computer Lab devoted primarily to geographic information systems (GIS) activities. The library, without walls, serves as a repository of digital geographic data (in addition to traditional maps and atlases, as well as collections in the disciplines of cartography and GIS). The lab provides the means of analyzing and mapping these data with GIS software and state-of-the art computer facilities. The new GIC cost over $\$ 280,000$, with generous contributions from the Dean of Science, Alan Shaver, and the Director of Libraries, Frances Groen.

This exciting new partnership between the Faculty of Science and the McGill University Libraries has enabled the University to bring together a team of GIS "experts" whose mission is to further the cause of GIS literacy at McGill. There are approximately 60 computers, many of these being Pentium 200 MMXs with 17 inch monitors attached to a new file server and Lexmark colour laser printer. Digitizing and scanning equipment is also available. There is an interactive classroom for teaching GIS, data retrieval and Web navigation. The instructor's computer is permanently connected to a SONY computer projection system. GIS software includes ESRI's Arcview 3.1, and accompanying Network Analyst and Spatial Analyst modules, Map Info 4.1 and Idrisi 4 for Windows.

The GIC is open seven days a week in term time. Graduate students in the Department of Mathematics, Geography and Atmospheric and Oceanic Sciences, as well as selected undergraduates, have the additional advantage of 24 hour access using a swipe card and PIN system.

The library's Web page gives details on collections and services, 
http://www.geog.mcgill.ca/heeslib/welcome.html

The Hitschfeld Hotlist, contained therein, evaluates, organizes and provides access to authoritative Web sites in the fields of cartography, geographic information systems, remote sensing, geography, environmental studies, global change and pertinent "virtual" reference sources.

Naming the library in honour of Waiter Hitschfeld is eminently fitting. Dr. Hitschfeld not only set the tone and the standard for research within McGill as Dean of Graduate Studies and Vice-Principal Research, but also became a respected advocate on the national scene for the importance of science education and research. The name serves as a reminder of the connection between Walter Hitschfeld and McGill University. 